\title{
ADDITIVE $s$-FUNCTIONAL INEQUALITIES AND PARTIAL MULTIPLIERS IN BANACH ALGEBRAS
}

\section{CHOONKIL PARK}

Abstract. In this paper, we solve the additive $s$-functional inequalities

$$
\|f(x+y-z)-f(x)-f(y)+f(z)\| \leqslant\|s(f(x-y)+f(y-z)-f(x-z))\|,
$$

where $s$ is a fixed nonzero complex number with $|s|<1$, and

$$
\|f(x-y)+f(y-z)-f(x-z)\| \leqslant\|s(f(x+y-z)-f(x)-f(y)+f(z))\|,
$$

where $s$ is a fixed nonzero complex number with $|s|<1$.

Furthermore, we prove the Hyers-Ulam stability of the additive $s$-functional inequalities $(0.1)$ and $(0.2)$ in complex Banach spaces. This is applied to investigate partial multipliers in Banach $*$-algebras and unital $C^{*}$-algebras, associated with the additive $s$-functional inequalities $(0.1)$ and $(0.2)$

Mathematics subject classification (2010): 39B52, 46L05, 39B62, 43A22. inequality.

Keywords and phrases: Partial multiplier in $C^{*}$-algebra, Hyers-Ulam stability, additive $s$-functional

\section{REFERENCES}

[1] T. AOKI, On the stability of the linear transformation in Banach spaces, J. Math. Soc. Japan 2 (1950), 64-66.

[2] W. FeChNER, Stability of a functional inequalities associated with the Jordan-von Neumann functional equation, Aequationes Math. 71 (2006), 149-161.

[3] P. GǍVRUTA, A generalization of the Hyers-Ulam-Rassias stability of approximately additive mappings, J. Math. Anal. Appl. 184 (1994), 431-436.

[4] A. GiLÁNYI, Eine zur Parallelogrammgleichung äquivalente Ungleichung, Aequationes Math. 62 (2001), 303-309.

[5] A. GiLÁnYi, On a problem by K. Nikodem, Math. Inequal. Appl. 5 (2002), 707-710.

[6] D. H. Hyers, On the stability of the linear functional equation, Proc. Nat. Acad. Sci. U.S.A. 27 (1941), 222-224.

[7] R. V. KADison AND J. R. Ringrose, Fundamentals of the Theory of Operator Algebras: Elementary Theory, Academic Press, New York, 1983.

[8] B. Khosravi, M. B. Moghimi and A. Najati, Generalized Hyers-Ulam stability of a functional equation of Hosszu type, Nonlinear Funct. Anal. Appl. 23 (2018), 157-166.

[9] G. KIM AND H. SHIN, Approximately quadratic mappings in non-Archimedean fuzzy normed spaces, Nonlinear Funct. Anal. Appl. 23 (2018), 369-380.

[10] Y. LEE AND S. JUNG, A general theorem on the fuzzy stability of a class of functional equations including quadratic-additive functional equations, Nonlinear Funct. Anal. Appl. 23 (2018), 353-368.

[11] Y. MANar, E. Elqorachi AND TH. M. Rassias, Hyers-Ulam stability of the Jensen functional equation in quasi-Banach spaces, Nonlinear Funct. Anal. Appl. 15 (2010), 581-603.

[12] Y. MANAR, E. ElQORACHI AND TH. M. RASSIAS, On the Hyers-Ulam stability of the quadratic and Jensen functional equations on a restricted domain, Nonlinear Funct. Anal. Appl. 15 (2010), 647-655.

[13] C. PARK, Homomorphisms between Poisson JC* -algebras, Bull. Braz. Math. Soc. 36 (2005), 79-97. 
[14] C. PARK, Additive $\rho$-functional inequalities and equations, J. Math. Inequal. 9 (2015), 17-26.

[15] C. PARK, Additive $\rho$-functional inequalities in non-Archimedean normed spaces, J. Math. Inequal. 9 (2015), 397-407.

[16] C. PARK, K. Ghasemi, S. G. Ghaleh AND S. JAng, Approximate n-Jordan *-homomorphisms in $C^{*}$-algebras, J. Comput. Anal. Appl. 15 (2013), 365-368.

[17] TH. M. Rassias, On the stability of the linear mapping in Banach spaces, Proc. Am. Math. Soc. 72 (1978), 297-300.

[18] J. RÄTZ, On inequalities associated with the Jordan-von Neumann functional equation, Aequationes Math. 66 (2003), 191-200.

[19] A. TAGHAVI, On a functional equation for symmetric linear operators on $C^{*}$-algebras, Bull. Iranian Math. Soc. 42 (2016), 1169-1177.

[20] S. M. Ulam, A Collection of the Mathematical Problems, Interscience Publ. New York, 1960. 